\section{Praticando a Geografia em ambientes não-escolares: uma experiência na orla fluvial de Belém-Pará}

Saint-Clair Cordeiro Trindade

Júnior *

Marcio Douglas Brito Amaral**

Bruno Cezar Pereira Malheiro***

Resumo: $\mathrm{O}$ artigo discute a experiência de geógrafos pesquisadores a partir da interação com a vivência cotidiana de sujeitos produtores do espaço em feiras, portos e trapiches presentes na orla fluvial de Belém (Pará). Tal experiência mostra a possibilidade de um diálogo construtivo que articula saberes acadêmicos àqueles elaborados no seio de vivências cotidianas e de suas organizações. Além do estudo da geografia cotidiana dos sujeitos presentes em três realidades particulares da orla sul da cidade, foram consideradas suas formas de organização, bem como o potencial participativo e de reflexão política dos mesmos face às demandas sócio-espaciais existentes e às propostas de intervenção do poder público na orla fluvial de Belém. A experiência revela, igualmente, a possibilidade de interação entre universidade e realidades urbanas específicas, bem como a instrumentação recíproca por meio do exercício para a formação profissional em Geografia e para a formação política cidadã.

\section{Practicing Geography in non-school environments: an experiment on river's edge in Belem-Pará}

\begin{abstract}
The paper discusses about the researchers geographers experience from interaction with the everyday life of the space producers subjects in fairs, ports and wharfs that there are in Belem fluvial edge (Pará). This experience shows the possibility of a constructive dialogue that links academic knowledge to those are produced within everyday lives and their organizations. Beyond the study of the subjects everyday geography present in three particular realities on city southern edge, it was considered their organization forms as well as their participatory potential and political reflection concerning about sociospatial demands existing and proposed government intervention on Belem river's edge. The experience shows also the possibility of interaction between university and specific urban realities as well as the reciprocal instrumentation through the exercise for professional training in Geography and for citizen political training.
\end{abstract}

* Professor Associado IV do Núcleo de Altos Estudos Amazônicos (NAEA) da Universidade Federal do Pará (UFPA). Doutor em Geografia Humana pela Universidade de São Paulo (USP) com PósDoutorado em Políticas Urbanas no Institut des Hautes Études de l' Amérique Latine (Université Paris III/Sorbonne Nouvelle).

** Professor do Depatamento de Geografia da UFPA. Doutor em Geografia pela USP.

*** Professor da Faculdade de Educação da UFPA Campus Marabá. Mestre em Planejamento do Desenvolvimento pela UFPA.

\section{Palavras-chave:}

Geografia, ambientes nãoescolares, orla fluvial, BelémPará.

Key-Words:

Geography, non-school environments, river's edge, Belem-Pará. 


\section{Intodução}

1 A discussão aqui proposta é resultado de alguns anos de pesquisa, por nós realizada, sobre a orla fluvial de Belém no Departamento de Geografia da Universidade Federal do Pará, com sistematização já publicada em forma de livro (TRINDADE JR; SILVA, 2006). As interpretações sistematizadas são resultantes, nesse sentido, de reflexões produzidas, primeiramente, no interior do projeto "Apropriação do espaço e controle do uso do solo na orla fluvial de Belém: intervenções, planejamento e gestão urbana" e, em um momento posterior, do projeto "Espaço e cidadania na orla fluvial de Belém: praticando a Geografia em ambientes não-escolares". O primeiro sendo finalizado no final do ano de 2004, após dois anos de vigência e, o segundo, em 2006

${ }^{2}$ Inspirado nos princípios da pesquisa-ação (THIOLENT, 1996), o projeto foi Financiado pelo Programa Integrado de Apoio ao Ensino, Pesquisa e Extensão (PROINT) e coordenado pelo Prof. Dr. Saint-Clair Cordeiro da Trindade Jr., sendo integrantes da equipe de pesquisa, ensino e extensão, além dos demais autores deste artigo, o geógrafo e sociólogo Marcos Alexandre Pimentel da Silva e os bolsistas de iniciação científica, Beatriz Vilar, Tiago Veloso e Rovaine Ribeiro, graduandos do curso de Geografia da Universidade Federal do Pará por ocasião do desenvolvimento do projeto.

A Região Metropolitana de Belém (RMB) é formada pelos Municípios de Belém, Ananindeua, Marituba, Benevides e Santa Bárbara.

Geografia Ensino \& Pesquisa, v. 18 n.1, p. 85-98, jan./abr. 2014

Praticando a Geografia em ambientes não-escolares: uma experiência na orla fluvial de Belém-Pará
Tradicionalmente o ensino de geografia tem sido praticado em ambientes escolares ou formais, especialmente aqueles voltados para o nível fundamental e médio. Em que pese a importância desse público-alvo para o qual se destina a formação do geógrafo-educador, têm sido cada vez maior as demandas da sociedade quanto ao embasamento que a geografia possa dar com vistas à formação cidadã, inclusive em ambientes não-escolares, a exemplo daqueles formados por organizações não-governamentais, movimentos sociais e associações de bairro.

Em uma sociedade marcada pela desigualdade e pela injustiça social, em que se verificam diferenciações de classe, de gênero, de cultura etc., a pesquisa social passa a apresentar novos desafios, de maneira a aliar a formação técnica ao compromisso político eético, tendo em vista a possibilidade de uma práxis transformadora. Isso pressupõe o envolvimento não apenas da dimensão da prática de ensino e do currículo, mas também da pesquisa científica, com vistas a um compromisso social, ético e político.

Considerando essas premissas, procurou-se refletir sobre o papel da Geografia em um contexto amazônico tangenciado por uma dinâmica de exclusão social. Dentro dessa perspectiva, foi iniciado um estudo ${ }^{1}$ desenvolvido por pesquisadores do Departamento de Geografia da Universidade Federal do Pará, inserido em um "Projeto Integrado de Ensino, Pesquisa e Extensão"2.

Pensado após alguns anos de investigação científica sobre a temática da produção do espaço na orla fluvial de Belém, buscou-se aprofundar o conhecimento de três espaços de forte identidade territorial ribeirinha e residualmente presentes no contexto metropolitano, a saber: o "Porto do Açấ", o "Porto da Palha" e o "Ponto Certo". Localizados na orla fluvial sul da cidade, banhada pelo rio Guamá, um dos rios que banham Belém, esses portos apresentam certa peculiaridade pela forte interação que promovem entre a metrópole belenense e o interior da Amazônia. Tratam-se não somente de portos ou ancoradouros ribeirinhos, mas de espaços que se articulam ao interior do tecido urbano por eixos estratégicos (rua Fernando Guilhon, travessa Padre Eutíquio e avenida José Bonifácio, respectivamente). Além dos trapiches onde ancoram os barcos, apresentam em seu entorno comércios e feiras, que fazem deles verdadeiros entrepostos comerciais e pequenos centros de abastecimentos dos bairros onde se localizam (Jurunas, Condor e Guamá, respectivamente), da cidade e da Região Metropolitana de Belém³.

A interação com o rio nesses espaços da orla de Belém, expressa, no contexto metropolitano em que se inserem, resíduos da cidade ribeirinha que subsiste no contexto urbano atual, contrapondo-se à padronização da cidade "beira-rio", apresentada como vitrine nas recorrentes obras de intervenção urbanística, notadamente na orla central da cidade. O potencial daqueles espaços como formas de preservação da cidade ribeirinha e como indicadores de novos padrões urbanísticos pouco articulados às práticas atuais de planejamento e de gestão da cidade, aponta para uma estratégia de política urbana que leve em conta a participação e o envolvimento dessas vivências a partir das sociabilidades configuradas.

Nesse sentido, tornava-se importante reconhecer e analisar a espacialidade e a territorialidade da vida cotidiana que se manifestava na orla fluvial de Belém, tomando-a como ponto de partida para o exercício do planejamento e da gestão urbana e como espaços em potencial para a formação profissional em Geografia.

Dessa maneira, tinha-se como intuito promover uma aproximação com os agentes produtores desses espaços e de suas vivências cotidianas, de modo que, a partir desse contato, fosse possível se estabelecer, para além da troca de informações sobre a realidade objeto de estudo, um diálogo construtivo por meio do qual os resultados da pesquisa fossem expostos e, concomitantemente, realimentados, servindo como elementos de reflexão para os próprios sujeitos constituintes dessa mesma realidade. Trata-se, portanto, de uma prática diferenciada de se fazer Geografia, que envolve pesquisa e extensão e que leva em conta a relação ensinoaprendizagem, fora, entretanto, de ambientes escolares formais. 
Este artigo, assim, procura sistematizar elementos dessa experiência, destacando os agentes envolvidos, as técnicas e procedimentos utilizados no processo de aproximação e de interação com esse ambiente não-escolar, as dificuldades enfrentadas nesse processo, bem como as novas possibilidades de instrumentação técnico-científica e política por meio do contato entre saberes acadêmicos e cotidianos, dialeticamente articulados.

\section{A realidade objeto de preocupação e de interação}

A orla de Belém condensa relações e objetos socioespaciais/geográficos que, considerados em conjunto, traduzem na atualidade, uma síntese dos tempos que presidiram a produção do espaço amazônico e belenense. Neste sentido, há uma relação muito estreita entre os objetos e os contextos dos quais os mesmos são produtos.

Essa materialização se expressa desde as primeiras relações baseadas no comércio das "drogas do sertão" e que definiram as primeiras funcionalidades da orla como expressão intraurbana da rede de cidades que se formava na Amazônia e na qual Belém assumiu o papel de cidade primaz. O mesmo pode-se dizer durante a influência da economia da borracha, seja no seu apogeu, seja no seu declínio, por meio de tentativas de revitalização da importância daquele produto.

As políticas territoriais iniciadas a partir da década de 1960 para a região, expressam, na caracterização atual da orla, a importância dos incentivos fiscais do governo federal e do processo de integração para a dinâmica regional e local das últimas décadas; presentes na paisagem da orla por meio de empreendimentos privados, de portos e demais atividades econômicas incentivadas por órgãos como a então Superintendência do Desenvolvimento da Amazônia (SUDAM).

Mais recentemente, as novas tendências de desenvolvimento regional e local passam a definir, igualmente, uma série de intervenções na orla fluvial de Belém que demonstram os rebatimentos de processos mais gerais na organização desse espaço. Em todas essas situações, tratam-se de sistemas de objetos que, por meio do inventário das formas geográficas existentes, permitem-nos estabelecer uma periodização para compreender a complexidade de usos presentes nessa fração do espaço urbano belenense.

As mudanças mais recentes colocadas para o atual arranjo espacial da orla encontram inúmeras resistências para sua efetivação, sobretudo pela permanência dos usos já estabelecidos, o que constitui um entrave ao planejamento estatal e à substituição por usos voltados para o lazer e para o turismo, por exemplo. Assim, embora a ocupação privada predomine em quase toda a extensão da orla, a mesma ocorreu de maneira diferenciada segundo a dinâmica dos agentes produtores do espaço urbano, produzindo algumas especificidades reveladas pela tipologia de usos aí existentes, conforme observado na orla sul da cidade, onde dominam alguns traços de atividades e agentes mais ligados à face "ribeirinha" da cidade e ao "circuito inferior da economia urbana" (SANTOS, 1979).

Faz-se necessário, portanto, olhar para a vida cotidiana que se espacializa na orla fluvial tomando-a como ponto de partida para o exercício de planejamento e de gestão urbanos mais inclusivos e como forma de inserção participativa dos agentes que cotidiana e regularmente interagem com o rio definindo outra lógica de apropriação do espaço que merece um deslocamento de olhares.

Nesse sentido, para além do espaço concebido pelo planejamento e para uma determinada prática de gestão urbana, a orla fluvial de Belém apresenta uma dimensão cotidiana que se expressa materialmente por meio de uma paisagem e de um espaço vivido (LEFEBVRE, 1974) ligado às necessidades de sobrevivência econômica e de expressões sociais com fortes apelos culturais, reveladores das singularidades locais e das particularidades regionais.

Geografia Ensino \& Pesquisa, v. 18, n.1, p. 85-98, jan./abr. 2014.

Trindade Jr., S.C.; Amaral, M. D. B.; Malheiro, B. C. P.

ISSN 2236-4994 | 87 
A interação com o rio nesses espaços de vivência, expressa, no contexto metropolitano em que se inserem, resíduos da cidade ribeirinha que subsiste e que resiste no contexto urbano atual, especialmente na faixa de orla da cidade, contrapondo-se, no plano de seu sistema de objetos (paisagem) e de seu sistema de ações (relações) (SANTOS, 1996), à padronização da cidade beira-rio apresentada como vitrine por meio das obras de intervenção urbanística, notadamente na orla central da cidade.

Assim, o conhecimento das estruturas ligadas às estratégias de planejamento e gestão e ao poder de decisão, tanto municipal como estadual, precisam estar ao alcance desses agentes, seja do ponto de vista técnico, seja do ponto de vista político; daí a importância da ciência, e da Geografia em específico, como uma forma de saber que pode contribuir para potencialização do saber cotidiano. Isso requer, além da sistematização científica, a sistematização de práticas pedagógicas, não nos moldes da escola formal, mas em outros termos, que reconheçam as especificidades dos sujeitos envolvidos.

Nesse sentido, a experiência desenvolvida buscou aprofundar o conhecimento dessa realidade anteriormente mencionada com intuito de promover uma aproximação com os agentes produtores desses espaços e de suas vivências cotidianas a partir dos seguintes procedimentos:

a) levantamento e sistematização de informações e dados empíricos sobre as realidades específicas selecionadas, para fins de análise e interação prática na orla fluvial de Belém;

b) planejamento das atividades em nível de ensino e extensão, que foram realizados junto aos sujeitos pesquisados, como também, junto a alunos do curso de Geografia da Universidade Federal do Pará;

c) realização de aulas/oficinas envolvendo a equipe do projeto, especialmente os bolsistas/estagiários que atuaram no campo de estágio, tendo em vista as realidades empíricas pesquisadas; discussão de conteúdos e metodologias de ensino voltados para ambientes não-escolares, com elaboração de materiais e recursos didáticos que foram utilizados nas oficinas realizadas junto à comunidade;

d) realização dos primeiros contatos entre os estagiários e a comunidade, de maneira a ambientá-los nos campos de estágio, possibilitando com isso a efetivação, em seguida, das oficinas e outras atividades que permitiram não só a interação da Universidade com a comunidade, como também o exercício prático por parte dos alunos do curso de Geografia envolvidos no projeto;

e) realização de atividades entre a equipe do projeto e turmas do curso de Geografia, onde estavam sendo ministradas as disciplinas Metodologia do Ensino de Geografia, Prática de Ensino de Geografia e Seminário de Atualização Geográfica, bem como realização de palestras e debates em escolas de ensino fundamental e médio, públicas e privadas, de Belém.

\section{Da realidade teorizada à prática pedagógica}

Geografia Ensino \& Pesquisa, v. 18, n.1, p. 85-98, jan./abr. 2014.

Praticando a Geografia em ambientes não-escolares: uma experiência na orla fluvial de Belém-Pará
Refletir sobre a prática de ensino em geografia significa não apenas mostrar como ela se apresenta concretamente, mas também como ela poderia se apresentar, o que sugere uma reflexão sobre a mesma. De acordo com Saviani (1998), a reflexão deve ser rigorosa, radical e de conjunto. Rigorosa porque utiliza métodos científicos historicamente produzidos pelo saber acadêmico e que funcionam como uma ferramenta, que permite uma melhor aproximação do real. Radical, no sentido de que busca a raiz do problema, sua substância, aquilo que explica a sua existência, a sua essência. Apresenta-se como totalidade, na medida em que não desloca o problema específico de sua dimensão macro, não separa o entendimento da parte de uma visão do todo, procurando mostrar que, por mais específico que seja o problema, ele está relacionado a uma dimensão de totalidade; isto sem perder de vista a dimensão da ação (SAVIANI, 1998).

É nesse sentido que a experiência em foco buscou promover um movimento dialético entre o fazer e o pensar sobre o fazer. Dessa forma, trata-se da práxis (ação-reflexão-ação sobre a realidade). A ação mobiliza a reflexão, que, por sua vez, retorna à ação. Na medida em que esta 
última é mobilizada, ela própria sugere reflexões, que por sua vez, buscam voltar-se à ação. Neste momento, não se trata mais de ação espontânea, mas refletida.

Para Freire (1997), esta é a primeira condição para que um sujeito assuma verdadeiramente o compromisso com a transformação social (socioespacial): ação e reflexão. Nas suas palavras:

É preciso que seja capaz de, estando no mundo, saber-se nele. Saber que, se a forma pela qual está no mundo condiciona a sua consciência deste estar, é capaz, sem dúvida, de ter consciência desta consciência condicionada. Quer dizer, é capaz de intencionar sua consciência para a própria forma de estar sendo, que condiciona sua consciência de estar (FREIRE, 1997, p. 16).

Dessa forma, a prática de ensino de caráter transformador sugere refletir sobre a relação que se estabelece entre os seres humanos e a realidade na qual estão inseridos, pois, ao mesmo tempo em que a sociedade produz seu espaço, ela é por ele produzida. Assim, antes de projetar qualquer ação transformadora no espaço, faz-se necessária a compreensão desse espaço e de seu processo de produção. A ação não se dá de forma ingênua. Toda prática de ensino deve ser compreendida como uma práxis; daí a importância do suporte da pesquisa científica:

Somente um ser que é capaz de sair de seu contexto, de "distanciar-se" dele para ficar com ele; capaz de admirá-lo para, objetivando-o, transformá-lo e, transformando-o, saber-se transformado pela sua própria criação; um ser que é e está sendo no tempo que é o seu, um ser histórico, somente este é capaz, por tudo isto, de comprometer-se (FREIRE, 1997, p.17).

Diante disso, pode-se afirmar que a prática de ensino exige além de um compromisso político, segurança ou domínio da técnica. Se por um lado, não se pode reduzir a prática de ensino a uma relação tecnicista, em que a técnica se transforma em uma mitificação; por outro lado, o compromisso político sem capacidade técnica de intervenção na realidade também é mito e não se sustenta, pois agir sem rigorosidade pode se tornar ingenuidade. Deve-se, portanto, aliar ao conhecimento técnico um comprometimento político com a transformação da realidade geográfica. Como afirma Freire:

Se o meu compromisso é realmente com o homem concreto, com a causa de sua humanização, de sua libertação, não posso por isso mesmo prescindir da ciência, nem da tecnologia, com as quais me vou instrumentando para melhor lutar por esta causa (FREIRE, 1997, p. 23).

Ao discutir também a importância da reflexão-ação na prática de ensino, Perrenoud (2002) procura distinguir três níveis de reflexão: a reflexão na ação, a reflexão sobre a ação e a reflexão sobre o sistema de ação. A primeira se refere à reflexão realizada no "calor da ação", momento em que não se pode parar a ação e refletir. A segunda refere-se à reflexão realizada distante do "calor da ação". Neste caso, torna-se a própria ação como objeto de reflexão, seja para compará-la com outras ações, seja para criticá-la ou explicá-la. No geral, essa reflexão é retrospectiva (entender o que foi feito) e prospectiva (propor ações futuras melhores). A terceira, faz alusão ao sistema de ação, ou seja, trata-se de uma reflexão que é feita sobre a estrutura da ação de um sujeito, sobre o sistema de ação do qual faz parte.

Para Perrenoud (2002), a reflexão deve transformar-se de ações esporádicas para o fundamento da própria prática educativa. Neste sentido é que o autor considera imprescindível o diálogo com o conceito de habitus e, citando Bourdieu, considera ser um conjunto de esquemas responsáveis por gerar uma diversidade de práticas adaptadas às ações que se renovam. Tratamse de atos que foram incorporados de tal maneira à nossa prática que nós já nem percebemos:

Não somos conscientes de todos os nossos atos e, acima de tudo, não temos consciência de que nossos atos seguem estruturas estáveis. Muitas vezes, a falta de uma consciência clara é "funcional": nossos esquemas nos permitem agir de modo imediato, quase no piloto automático, o que é mais econômico psiquicamente, pelo menos enquanto não nos deparamos com um obstáculo não-habitual (PERRENOUD, 2002, p. 39).

Geografia Ensino \& Pesquisa, v. 18, n.1, p. 85-98, jan./abr. 2014.

Trindade Jr., S.C.; Amaral, M. D. B.; Malheiro, B. C. P.

ISSN 2236-4994 | 89 
Pensar a partir dessas premissas, significa não abrir mão de uma prática reflexiva no ofício de professor. Não se trata de refletir de forma esporádica, mas de tornar a reflexão parte da ação educativa, de maneira que a mesma seja feita com rigor metodológico, regular e instrumentalizada, pois é uma ação consciente, profissionalizada.

Na geografia muitas têm sido as dificuldades enfrentadas para o desenvolvimento da prática de ensino. De acordo com Pontuschka (1999),apesar dos avanços nas discussões acadêmicas e na produção de material didático-pedagógico na prática de ensino de geografia, muitas dificuldades são recorrentes, dentre as quais:

a.Domínio dos conhecimentos geográficos a serem ensinados: conhecimento das categorias de análise da geografia e de como utilizá-las no ensino, pois não basta fazer a leitura do espaço geográfico de maneira geral, é necessário fazer uma interpretação da realidade específica dos educandos e da forma como os mesmos entendem a realidade geográfica;

b.Conhecimentos didático-pedagógicos que possibilitem a utilização de métodos e técnicas de ensino e conhecimentos psicológicos que permitam entender melhor o educando. Para desenvolver uma prática de ensino em geografia não basta apenas conhecer os conteúdos e os métodos específicos da disciplina, é necessário transpor as fronteiras e dialogar com as singularidades do ensinar;

c. Domínio dos métodos de construção da geografia. É necessário conhecimento de como fazer pesquisa em geografia e, através do seu ensino, como produzir conhecimentos geográficos na escola, pois o aluno precisa apropriar-se dos métodos de análise do espaço geográfico desenvolvidos pela ciência geográfica.

d. Domínio dos diversos documentos que fundamentaram a constituição da geografia e que lhe serve de sustentação científica: pesquisas empíricas, inventários, vídeos, mapas, gráficos, tabelas, sensoriamento remoto, informática etc. $\mathrm{O}$ uso das mais variadas linguagens pode contribuir para a compreensão e a crítica do espaço geográfico.

Além dessas dificuldades da prática de ensino de geografia apresentadas por Pontuschka (1999), cabe destacar outra ressaltada por Rocha (2004). Para este autor, muitas vezes, os professores de geografia não realizam suas atividades docentes de forma intencional, conscientes de sua ação, pois falta clareza do por que ensinar Geografia, posto que não se domina os pressupostos da prática docente. Muitas vezes a ação docente é realizada de maneira ainda muito espontânea, não havendo uma profissionalização no sentido de saber que o ensinar está relacionado a um projeto de construção social. O trabalho que é realizado em sala de aula pode ser um instrumento de transformação ou de legitimação da realidade existente.

Rocha (2004) ressalta ainda que a prática de ensino de geografia não se realiza apenas na sala de aula convencional, mas também em outros espaços, dentre os quais ele destaca a educação indígena, a educação especial e a educação de jovens e adultos. Além desses, é preciso acrescentar, ainda, os ambientes não-escolares, que serão abordados a partir de agora.

\section{Da realidade estudada à realidade vivenciada}

Geografia Ensino \& Pesquisa, v. 18, n.1, p. 85-98, jan./abr. 2014.

Praticando a Geografia em ambientes não-escolares: uma experiência na orla fluvial de Belém-Pará
A experiência da prática de Geografia em ambientes não escolares direcionou-se, como dissemos anteriormente, a três lugares específicos localizados na orla fluvial de Belém, mais especificamente na extremidade sul dessa mesma orla. Tais lugares já figuravam como campos empíricos de nossa análise em um momento anterior e, por isso, já havíamos produzido interpretações sistemáticas a respeito dos mesmos.

Os trabalhos anteriores mostraram que a cidade de Belém sintetiza o encontro de mundos 
diversos, lógicas distintas, temporalidades múltiplas em sua faixa de orla que, enquanto mediação entre a metrópole e as águas/floresta, apresentava-se na correlação entre padrões gerais de produção/consumo e expressões sociais com fortes apelos culturais/simbólicos.

Os espaços para os quais as atividades foram direcionadas apresentavam-se para nossas análises, portanto, como expressões socioculturais que se produziam a partir de uma dinâmica de contato/dependência com o rio, expressando um encontro de temporalidades distintas em situações para além da sobrevivência. Esses lugares colocavam-se como resíduos de vida urbana, não se reduziam a um tempo hegemônico da reprodução do valor de troca, assumindo uma dimensão de obra, na qual o valor de uso mostrava-se por meio de sociabilidades próximas entre os sujeitos, em trocas que pressupunham o encontro, o reconhecimento mútuo, o lúdico, presentes de maneira flagrante na vida urbana criada.

As feiras, portos e trapiches que se colocavam para nossas reflexões apresentavam uma importância ímpar para a cidade, não apenas do ponto de vista do abastecimento de produtos, como o açaí, por exemplo, um produto muito presente na gastronomia paraense e amazônica, mas, colocavam-se também como importantes pela vida e trabalho que produziam, pela resistência e persistência às margens do rio, pela produção de uma diferenciação socioterritorial, principal atributo de uma identidade territorial ribeirinha, pela imagem de cidade que projetavam; imagem que, muitas vezes, ou quase sempre, tem sido ignorada pelo poder público.

Foi a partir dessas conclusões que a aproximação aos espaços se fez necessária, não como forma de intervenção na realidade, mas como possibilidade de diálogo com os agentes em que o tema central seria a vida, o trabalho e o espaço nos lugares estudados; de modo que a partir desse mote alguns resultados da pesquisa seriam expostos e discutidos, em uma busca de interação de ensino-aprendizagem, baseada em uma troca de experiências.

A preocupação inicial girou em torno da forma pela qual poderíamos nos aproximar da realidade para os fins propostos, de tal sorte que não se criasse a forte imagem do outro e de seu caráter unidirecional com relação à sistematização e domínio de saberes, mas principalmente como mediadores e facilitadores de conhecimentos e problematizadores da realidade junto aos agentes envolvidos. A incursão assemelhava-se àquela que toma forma nas classes escolares formais somente quanto aos objetivos de apresentação e problematização do conhecimento científico, mas diferenciava-se substancialmente quanto ao contexto (um ambiente não-escolar), aos agentes (trabalhadores, lideranças, "usadores" e moradores dos portos) e ao perfil de vivência, trajetória de vida e de politização dos mesmos.

As peculiaridades dos lugares, os diferentes graus de instrução dos sujeitos, a diversidade de mundos que se apresentavam, as diferentes expectativas em relação à nossa presença, colocavamse como desafios a serem enfrentados em um primeiro momento. Não se tratavam de cursos regulares e formais com os quais já estávamos acostumados a lidar nas classes formais de ensino, mas de outra relação de ensino-aprendizagem em um contexto completamente diferenciado; fato este que nos conduziu à sistematização de metodologias alternativas, na forma de oficina e atelier, por exemplo, com vistas a essa aproximação da realidade, marcadas conjuntamente, conforme já mencionamos, pela espontaneidade da vida cotidiana, pela presença do rio, do barco, da floresta, da metrópole, nas diversas formas de troca - de mercadorias, de narrativas, de histórias, de estórias, de sociabilidades, de necessidades. Daí identificarmos esses espaços como lugares - no sentido geográfico do termo - de (sobre)vivências.

As duas primeiras atividades pensadas tiveram uma mesma estrutura e foram direcionadas aos espaços do "Porto da Palha" e do "Porto do Açấ". A primeira atividade foi realizada no "Centro Comunitário do Porto da Palha". Dada à existência de uma organização política e comunitária, foram feitos recorrentes contatos anteriores com as lideranças e seus representantes, após uma ambientação e relativa vivência dos pesquisadores/facilitadores no dia-a-dia da feira e do porto.

Após o estabelecimento do local de realização, foi iniciada uma divulgação da atividade no espaço do Porto a partir de conversas informais, da fixação de cartazes e da distribuição de

Geografia Ensino \& Pesquisa, v. 18, n.1, p. 85-98, jan./abr. 2014.

Trindade Jr., S.C.; Amaral, M. D. B.; Malheiro, B. C. P.

ISSN 2236-4994 
${ }^{4}$ A identificação da atividade foi semelhante nos três espaços trabalhados, com algumas adaptações de acordo com as especificidades e toponímias de cada porto/ feira/trapiche.

Geografia Ensino \& Pesquisa, v. 18, n.1, p. 85-98, jan./abr. 2014.

Praticando a Geografia em ambientes não-escolares: uma experiência na orla fluvial de Belém-Pará folhetos descrevendo a atividade que, por sua vez, realizou-se em um sábado.

A expectativa de presença, após uma intensa divulgação, era otimista por parte do grupo mediador e das lideranças, mas o que se desenhou na realidade foi uma participação reduzida, aquém do esperado. Embora o Porto se mostrasse relativamente movimentado, algumas pessoas preferiram, por necessidade, continuar no seu trabalho, o carteado do final de semana, tão comum na realidade do Porto, o encontro no bar com os amigos, a longa conversa com os conhecidos do próprio Porto, a uma atividade denominada de "Porto da Palha: meu trabalho, minha vida" - fora do seu ritmo cotidiano, ainda que diretamente relacionada ao seu dia-a-dia. Deve-se destacar, porém, que apesar do número pequeno de participantes, os que se fizeram presentes mostraram-se motivados com a discussão e apresentavam bastante interesse para com a atividade.

Antes do relato propriamente dito dessa prática, é necessário esclarecer os procedimentos e os recursos pensados pelo grupo mediador e devidamente sistematizados e preparados a partir de um plano de atividades, semelhante ao que convencionalmente se denomina de "plano de aula", com envolvimento de sete pessoas, identificados como mediadores/facilitadores.

Com base na técnica de grupo focal teríamos, portanto, dois mediadores que conduziriam as discussões e metodologias programadas, um outro responsável por filmar a atividade e outro por fotografar. Teríamos, ainda, dois que ficariam responsáveis pela gravação das falas e outro que teria a incumbência de anotar suas impressões.

A atividade iniciou com um dos mediadores esclarecendo os objetivos que conduzia a equipe a realizar aquele tipo de trabalho, bem como apresentando, em linhas gerais, o projeto de pesquisa-extensão. O recurso utilizado, nesse primeiro momento, objetivava envolver os sujeitos na discussão e em relação à temática que se desejava desenvolver e, assim, motivá-los a participar das dinâmicas programadas. Tratava-se da apresentação de um curta-metragem sobre a cidade de Belém, sua orla fluvial e sua relação com o rio e com a floresta, produzido por pesquisadores da Universidade Federal do Pará.

A temática abordada a partir do vídeo proporcionou um momento de grande interação entre o grupo de pesquisa-extensão e os sujeitos presentes, dada à importância e à relação dos elementos abordados no curta-metragem com a vida cotidiana das pessoas que trabalham, vivem e usam a orla fluvial, por meio da feira, do porto e do trapiche. Este momento foi importante igualmente para a exposição, por parte dos facilitadores, de alguns elementos relacionados à Geografia Física, Urbana, Econômica e Cultural da cidade e de sua orla.

Foram levantadas, ainda, algumas questões sobre o filme relacionadas à vida e ao trabalho dos presentes; questionamentos estes que os incentivaram às falas e aos depoimentos sobre sua realidade, suas demandas cotidianas, bem como sobre as principais dificuldades enfrentadas cotidianamente. A interação ocorria através do diálogo em que, além de esclarecimentos, eram apresentadas sistematizações/contribuições do conhecimento geográfico, seguidos de novas problematizações da realidade.

Como forma de aproveitar o momento de diálogo, foi prevista e realizada a construção de um painel de fotografias sobre a orla fluvial de Belém, a partir dos seguintes procedimentos:

1. Em um primeiro momento foram distribuídas, para todos os participantes, várias fotografias registradas em momentos anteriores da pesquisa e que retratavam a paisagem complexa, diversificada e contraditória da geografia urbana da orla fluvial de Belém, algumas das quais o vídeo já havia mostrado;

2. Após essa distribuição, um dos facilitadores solicitou que cada participante escolhesse duas fotos: aquela que ele mais se identificou e aquela que ele menos se identificou;

3. Em um terceiro momento o outro mediador convidou a todos os participantes a colocarem as fotos escolhidas em um cartaz fixado na parede e que possuía duas colunas, uma para as fotos que os sujeitos se identificaram e outra para as fotos que eles não se identificaram; após a fixação das fotos por cada sujeito, era solicitada uma justificativa referente à escolha das fotos. 
Essa atividade foi planejada no sentido de trazer à tona as representações dos sujeitos em relação ao seu espaço de vida e trabalho. Foi pensada, ainda, no intento de produzir uma reflexão dos próprios participantes com relação aos espaços que identificavam sua vida e seu trabalho e, assim, assumiam importância do ponto de vista social, cultural e identitário. Aproximávamo-nos da realidade cotidiana vivenciada naquele espaço; começávamos, nesse sentido, a chegar mais próximo das experiências vividas por aqueles sujeitos.

Novamente, a intercalação de diagnósticos/depoimentos, problematização da realidade e sistematização de conhecimentos geográficos foi estabelecida; momento em que saberes acadêmicos (Geografia da Amazônia, Geografia Urbana, Geografia Cultural, Planejamento e Gestão Urbanos etc.) e cotidianos (vivências e experiências do porto, da feira e do trapiche) foram dialeticamente articulados.

Com a aproximação maior já estabelecida, a terceira parte da oficina/atelier foi direcionada à construção de outro painel, não mais com fotos, mas com cartões-postais da orla de Belém. Essa construção teve os seguintes passos:

1) Primeiramente foram distribuídos os cartões-postais para todos os participantes;

2) Em um momento segundo foi montada uma situação imaginária: um dos mediadores motivou os presentes, solicitando aos mesmos que se imaginassem como turistas que visitavam a cidade e que teriam que escolher um ponto turístico, representado nos cartões-postais, para visitar preferencialmente;

3) O outro mediador, em outro momento da dinâmica, pediu para que cada um dos presentes colocasse o cartão-postal escolhido no segundo cartaz e justificasse sua escolha;

4) Após a última justificativa foram feitos os seguintes questionamentos: qual o motivo da ausência do Porto da Palha nos cartões-postais? Por que esse espaço não estava em nenhum cartão postal se nele está viva e exposta a cultura amazônica? Por que as intervenções urbanísticas do poder público privilegiam e selecionam determinados espaços e não outros, a exemplo do Porto da Palha?

Esse momento foi fundamental para provocarmos uma discussão a respeito da importância daquele espaço para a cidade, para reconhecermos os processos de exclusão pelo qual o mesmo passou e passa, não apenas do ponto de vista econômico, mas também da política urbana, bem como para exposição de saberes relacionados às formas de planejamento e gestão que se apresentam hoje no Brasil e na cidade.

Esse diálogo também objetivou a relativização do termo cartão-postal, no sentido de mostrar o Porto da Palha como parte dos atrativos da cidade, não por sua beleza arquitetônica e urbanística, característica fundamental de todos os que foram vistos nas imagens apresentadas e problematizadas, mas pelo conteúdo de relações processadas, pela expressão de uma metrópole diferente que vive e trabalha tendo o rio como principal objeto/símbolo de seu cotidiano. Também contribuiu para estimular uma reflexão dos sujeitos presentes acerca de suas práticas espaciais, de seus espaços vividos e da necessidade de formas de planejamento e gestão mais participativas, democráticas e inclusivas que buscassem atender às demandas de infraestrutura existentes nos espaços de feiras, portos e trapiches e de melhoria da qualidade de vida e de trabalho nesses espaços da orla de Belém.

Para cumprir com a última etapa da atividade, ao final da construção do segundo painel, promovemos uma discussão a respeito de como instituições, a exemplo da Universidade, podem refletir sobre os problemas no Porto e de que maneira podem ajudar a pensar em políticas que atendam aos interesses das pessoas diretamente relacionadas à experiência cotidiana do mesmo.

Nesse momento da oficina/atelier foram consideradas tendências de planejamento e gestão urbanos colocados para Belém, além do levantamento das principais demandas cotidianas do espaço pelos sujeitos presentes, o que foi acompanhado de algumas sugestões dos mesmos no sentido de projetos para o Porto. O papel da universidade foi ressaltado como sendo fundamental do ponto de vista do esclarecimento científico e, também, da possibilidade de instrumentação

Geografia Ensino \& Pesquisa, v. 18, n.1, p. 85-98, jan./abr. 2014.

Trindade Jr., S.C.; Amaral, M. D. B.; Malheiro, B. C. P.

ISSN 2236-4994 
técnica e política, com relação a possibilidades de projetos de intervenção física e social a partir dos sujeitos que vivenciam esse espaço a ser direcionados à administração municipal em fóruns de participação e de tomada de decisão considerados democráticos.

A realização dessa discussão final revelou a possibilidade de diálogo aberto entre a universidade e os movimentos sociais, os ativismos de bairros, as organizações de moradores, enfim, revelou, para além da possibilidade, uma necessidade de maior contato, a partir de discussões produtivas, em que os dois lados têm a oferecer.

Considerando a primeira experiência de oficina/atelier em relação a essa realidade específica, essa atividade foi repetida, com alguns ajustes e aprimoramentos, no "Porto do Açấ".

Dada à inexistência de centro comunitário no próprio Porto, esta segunda experiência, por sua vez, não mais foi realizada no espaço da feira-porto, mas em uma escola pública próxima ao mesmo. A dinâmica, bem semelhante, produziu, inclusive, as mesmas dificuldades da primeira atividade, como a baixa presença dos sujeitos; nesse caso, não só porque os mesmos estavam, ou descansando ou trabalhando, mas devido à experiência não ter sido realizada no próprio espaço, que não disponibilizava de condições infraestruturais para o cumprimento dos objetivos da atividade didático-pedagógica proposta.

Ao final das duas atividades realizadas, percebemos, além da possibilidade de se produzir um interessante diálogo, o que já foi mostrado anteriormente, algumas dificuldades de aproximação às realidades e de participação dos sujeitos concernentes.

Esses percalços foram, até certo ponto, normais, considerando a falta de experiência de todos os envolvidos nas atividades com uma prática de Geografia em um ambientes não-escolar, dada a pouca difusão de trabalhos como esses no campo dessa ciência.

Talvez se possa dizer que há uma tendência de transportar para essas realidades específicas práticas didático-pedagógicas próprias de situações relacionadas à organização escolar formal, pautada ainda em uma centralidade dos mediadores/facilitadores e em uma forma de pedagogia que pressupõe a organização espacial da sala de aula e de seus recursos como indispensáveis a um processo de interação e de objetivação do processo ensino-aprendizagem.

A rigor, sugestionava-se trazer, ainda que de forma pouco ou nada intencional, uma organização espacial escolar para espaços vividos, praticados e experienciados a partir de outras referências organizativas, mesmo reconhecendo que os locais de realização das atividades foram previamente decididos com as pessoas que vivenciavam, trabalhavam e assumiam lideranças políticas nesses espaços da orla fluvial.

Tomando as experiências de maneira mais ampla podemos afirmar que, por um lado, a organização pensada ainda nos moldes de uma atividade formal de ensino-aprendizagem produziu um diálogo bastante produtivo com sujeitos interessados em discutir sobre sua realidade. Por outro lado, tal forma de organização das atividades consideradas pedagógicas em nível de projeto de pesquisa-extensão, de certa maneira, excluiu a maioria dos sujeitos produtores dos espaços em questão. Quiçá a falta de participação não tenha sido por um descompromisso do sujeito com sua realidade de vida e trabalho, mas pelo distanciamento produzido entre pesquisadores e a prática vivida por esses sujeitos; razão pela qual a terceira atividade ganhou contornos um pouco diferentes.

Geografia Ensino \& Pesquisa, v. 18, n.1, p. 85-98, jan./abr. 2014.

Praticando a Geografia em ambientes não-escolares: uma experiência na orla fluvial de Belém-Pará

\section{As exigências da prática: pensando em metodologias alternativas}

Tendo em vista todas essas dificuldades levantadas, colocou-se como imperativa uma nova forma de aproximação da realidade, o que acarretou uma reflexão acerca das metodologias utilizadas para estabelecer esse contato. Uma primeira necessidade que ganhava relevo referia-se 
à organização espacial pensada para a atividade: uma sala de aula, um centro comunitário ou o próprio espaço de vivência?

Se se estava querendo entender um pouco mais da vida e o trabalho daqueles homens e mulheres e, também, estabelecer um diálogo mais amplo sobre essa realidade vivida de forma a proporcionar a troca de saberes, incluindo reflexões científicas e as percepções e interpretações criadas dia-a-dia por aqueles sujeitos, colocava-se como imprescindível um contato maior, uma aproximação com as suas formas de sociabilidades, no sentido mais profundo e geográfico do termo.

A partir desses pressupostos, foi pensada, então, a realização da terceira atividade no próprio espaço, o "Ponto Certo", o terceiro dos três espaços pensados como campos de contato e interação. Dada à necessidade de contextualizar a realidade a partir de seu espaço e de seu tempo cotidianos, o dia de realização da atividade deveria ser, portanto, aquele de maior movimento desse lugar. "Disputaríamos" o pequeno espaço físico do trapiche com sacos de farinha, paneirosde açaí, múltiplos sujeitos trabalhando, cachos e mais cachos de banana etc. Lançávamos em uma empreitada mais ousada, aproximávamo-nos ao máximo da vida e trabalho, sobre os quais objetivávamos estabelecer um diálogo interativo motivados pela relação de ensino-aprendizagem mútuos.

Um primeiro desafio que se edificava era o de conseguir a atenção dos sujeitos que estavam trabalhando e vivenciando suas atividades cotidianas. Nesse sentido, pensamos em seduzir ao máximo os sentidos dos que ali estavam, trabalhando com painéis de fotografias, além de um baner, no qual estaria resumidamente uma apresentação da equipe e alguns tópicos mais relevantes da pesquisa; isso em uma linguagem objetiva e clara, de fácil compreensão para os nossos interlocutores.

Outro desafio colocado ligava-se à necessidade de descentralizar a atividade, ou seja, não fazer com que o ponto convergente da discussão fosse um ou dois mediadores/facilitadores. Era importante não fugir à organização espacial dos sujeitos, de modo a fazer com que eles chegassem a nós a partir de seus interesses. Caminhávamos para uma organização espacial não formal, mas vivida, cotidiana. Com esse objetivo, então, distribuímos os dois painéis e o baner em locais próximos, mas distintos, de maneira que ficassem dois mediadores/facilitadores nos arredores de cada um com o objetivo de descentralizar a discussão.

Após termos nos inserido na organização espacial do Porto, o que representou um desafio inicial, adentramos na experiência em si, no conteúdo da atividade e na forma como a mesma se desenrolou. Pela natureza dessa atividade, a equipe prescindiu do vídeo, utilizado nas atividades anteriores. Conforme já mencionado, a atividade girou em torno dos dois painéis preenchidos de várias fotos da orla de Belém, inclusive com fotos do "Ponto Certo", mais um baner, no qual figuravam algumas fotografias e uma apresentação do projeto de pesquisa-extensão. Como dito anteriormente, dois facilitadores ficaram em cada ponto específico e esperavam a aproximação dos interlocutores para iniciar um diálogo primeiramente individual, mas que gradativamente assumiam a perspectiva de uma socialização em grupos.

Esses diálogos, na realidade, tomaram o corpo de entrevistas semiestruturadas, num primeiro momento, nas quais algumas questões deveriam nortear a discussão, baseadas em preocupações como: a(s) foto(s) que mais estavam relacionadas ao dia-a-dia das pessoas e do porto; o porquê da seleção das fotos; a possibilidade ou não do "Ponto Certo" tornar-se um "cartão-postal" da cidade; o que seria necessário para que isso acontecesse; o distanciamento dos cartões-postais da realidade cotidiana da cidade e da vida dos portos, trapiches e feiras à beira-rio.

Tentávamos com essas preocupações, transformadas em questões diretas e coloquiais, atingir aos mesmos objetivos estabelecidos para as atividades anteriores, porém o contato produzido a partir do procedimento metodológico das entrevistas semiestruturadas, bem como a partir dos recursos didáticos utilizados (fotografias, baner e painéis) e da organização espacial mais espontânea e menos formal da atividade, foi bem maior se comparado com aquele proporcionado pelas outras atividades anteriormente realizadas.

Faz-se importante ressaltar que o fato das conversas terem sido levadas por caminhos informais, contribuiu em alguns momentos para ultrapassarmos os limites das perguntas

Geografia Ensino \& Pesquisa, v. 18, n.1, p. 85-98, jan./abr. 2014.

Trindade Jr., S.C.; Amaral, M. D. B.; Malheiro, B. C. P.

ISSN 2236-4994 
estabelecidas, chegando a discutir, com alguns, os modelos de planejamento e gestão colocados em prática na orla de Belém, a necessidade de se criar uma organização dos trabalhadores do "Ponto Certo", até então inexistente, a importância desse espaço para a cidade de Belém, dentre outros.

Porém, não avançamos apenas do ponto de vista dessas discussões estabelecidas, colhemos, ainda, vários relatos que nos mostraram, por exemplo, a importância daquele espaço a partir de histórias de vida ou trilhas geográficas, de luta e de extrema dificuldade contadas; fato que contribuiu, sobremaneira, para um diálogo mais próximo entre os envolvidos e o alcance de outros ângulos de visão da realidade vivida desses espaços, tão próximos da Universidade, que também se localiza na orla sul da cidade, e ao mesmo tempo tão distantes.

Por outro lado, o saber geográfico já sistematizado, objeto de nossas preocupações nessa experiência interativa, ainda que não tenha assumido a projeção que gostaríamos que tivesse assumido nesta última experiência, a exemplo do que se verificou, nas oportunidades anteriores, também não ficou relegado ao último plano, pois, no decorrer do diálogo entre os grupos que se formavam no entorno dos recursos, por nós tidos como didáticos e motivadores do processo de interação, ele era recorrentemente mobilizado, seja como forma de argumentação face à realidade problematizada, seja como elemento explicativo dos questionamentos que eram feitos como parte do diálogo desenvolvido.

Tratam-se, portanto, de duas formas de interação, que muito mais que contrapontos, mostram-se mesmo como complementares e que nem sempre as realidades contatadas mostram-se plenamente favoráveis a sua execução como prática de mobilização do conhecimento geográfico. Longe de serem práticas modelares, as experiências revelam muito mais limites e desafios a serem superados e pensados nos campos disciplinares que envolvem a preocupação com a prática de ensino de geografia em ambientes não-escolares, a exemplo do que foi verificado na experiência de pesquisa-extensão desenvolvida nos portos, feiras e trapiches da orla fluvial sul da cidade de Belém.

\section{À guisa de conclusão: construindo uma práxis geográfica?}

O que procuramos demonstrar com o relato dessas atividades é a potencialidade existente para se praticar a ciência geográfica em ambientes não-escolares, a partir da possibilidade de se inverter a posição do "pesquisador que domina o conhecimento" ao "cidadão problematizador da realidade".

Neste sentido, pensamos na possibilidade da construção de uma práxis geográfica, cujo sentido se dá pela inter-relação entre uma reflexão acerca da dimensão espacial da sociedade e uma ação de transformação desse espaço, sempre tomando como ponto de partida a responsabilidade social, ética e política do pesquisador-educador para com sua realidade de estudo. Falar, portanto, em práxis geográfica, nos termos aqui considerados, significa refletir sobre uma determinada realidade socioespacial, reconhecendo o quadro de exclusão e desigualdade social, pensando sempre em possibilidades de transformação.

Posto nesses termos, uma prática em ambientes não-escolares, enquanto práxis geográfica, requer, para sua realização, tanto conhecimentos acadêmicos, quanto conhecimentos pedagógicos para, assim, caminhar entre teoria e prática, entre universidade e sociedade, entre reflexão e ação.As

Geografia Ensino \& Pesquisa, v. 18, n.1, p. 85-98, jan./abr. 2014

Praticando a Geografia em ambientes não-escolares: uma experiência na orla fluvial de Belém-Pará atividades que nos propusemos a realizar nos mostraram, portanto, a possibilidade de uma maior interação, de um diálogo produtivo entre a Universidade e as mais variadas formas de movimentos sociais, ativismos de bairro e organizações coletivas e a necessidade de considerar as especificidades desses ambientes para avançar na proposição de metodologias que não sejam apenas colhedoras de informações, mas que possam problematizar a realidade estudada tornando-a um campo de reflexão e de proposição, tendo em vista a participação e o envolvimento dos próprios sujeitos, muitas vezes vistos apenas como fontes orais. 
A experiência revelou, portanto, o desafio e, ao mesmo tempo, a potencialidade, de ampliação dessa perspectiva dos sujeitos, que de informantes ocasionais, tornam-se também atores políticos que problematizam, questionam, refletem e propõem, quando levados a interagir com outras formas de saberes, num diálogo construtivo que estimula percepções cotidianas e acadêmicas a pensar a mesma realidade simultaneamente, atentando para uma aproximação da realidade e para o potencial de transformação dessa mesma realidade.

Do ponto de vista da formação profissional do geógrafo, a experiência abre a possibilidade de ação desse profissional em outros ambientes, para além da escola formal. Considerando a importância do saber geográfico na formação para a cidadania e as novas possibilidades de gestão e planejamento de caráter participativo que se apresentam, um novo desafio é colocado para os currículos de geografia, que se defrontam com uma realidade na qual a presença do geógrafo é cada vez mais recorrente e que não se satisfaz com a sistematização técnica e acadêmica desse conhecimento, demandando conhecimentos pedagógicos e didáticos.

Para isso é necessário pensar práticas e didáticas da geografia que se aproximem dessas outras necessidades cotidianas, onde a dimensão ensino-aprendizagem ganha outros contornos, que exigem do profissional em geografia uma postura de verdadeiro mediador e facilitador de saberes. Se esse desafio parece ser premente nos ambientes escolares formais, ele se coloca como verdadeiramente necessário e desafiador nos meios não-escolares, onde a presença de profissionais, como os da geografia, é igualmente importante.

\section{Referências}

FREIRE, Paulo. Educação e mudança. 21ª ed.. São Paulo: Paz e Terra, 1997.

LEFEBVRE, Henry. La productión de l'espace. Paris: Anthropos, 1974.

PERRENOUD, Phillipe. A prática reflexiva no ofício de professor: profissionalização e razão pedagógica. Porto Alegre: Artmed, 2002.

PONTUSCHKA, Nídia. Nacib. A geografia: pesquisa e ensino. In: CARLOS, Ana Fani Alessandri. (Org.).

Novos caminhos da geografia. São Paulo: Contexto, 1999. p. 111-142.

ROCHA, Genylton Odilon Rêgo. Práticas de ensino em Geografia. Rondon do Pará: Universidade Federal do Pará, 2004. (mimeo).

SANTOS, Milton. O espaço dividido: os dois circuitos da economia urbana dos países subdesenvolvidos. Rio de Janeiro: Francisco Alves, 1979.(Coleção Ciências Sociais).

A natureza do espaço: técnica e tempo, razão e emoção. São Paulo: Hucitec, 1996.

SAVIANI, Demerval. O debate teórico e metodológico no campo da história e sua importância para a pesquisa educacional. In: SAVIANI, Demerval; LOMBARDI, José Claudinei; SANFELICE, José Luís (Orgs.). História e história da educação: o debate teórico-metodológico atual.Campinas: Autores Associados/HISTEDBR, 1998. p.7-15.

Geografia Ensino \& Pesquisa, v. 18, n.1, p. 85-98, jan./abr. 2014.

Trindade Jr., S.C.; Amaral, M. D. B.; Malheiro, B. C. P.

ISSN 2236-4994 
TRINDADE JR., Saint-Clair Cordeiro da Trindade; SILVA, Marcos Alexandre Pimentel. Belém: a cidade e o rio na Amazônia. Belém: EDUFPA, 2006.

\section{Correspondência}

\section{Saint-Clair Cordeiro da Trindade Júnior}

E-mail: stclair@ufpa.br

Recebido em 17 de dezembro de 2012.

Revisado pelo autor em 23 de abril de 2014.

Aceito para publicação em 24 de abril de 2014.

Geografia Ensino \& Pesquisa, v. 18 n.1, p. 85-98, jan./abr. 2014

Praticando a Geografia em ambientes não-escolares: uma experiência na orla fluvial de Belém-Pará 